\title{
Coexistence of Miliary Tuberculosis with Tubercular Sacroiliitis in a Young Immunocompetent Female
}

\author{
Gaurav Sahu' ${ }^{1}$, Rounak Verma ${ }^{2}$, Sourya Acharya ${ }^{3}$, Samarth Shukla ${ }^{4}$, Sree Karthik Pratapa ${ }^{5}$
}

\begin{abstract}
${ }^{1}$ Department of Internal Medicine, Datta Meghe Institute of Medical Sciences (Deemed to be University), J. N. Medical College, Wardha, Maharashtra, India. ${ }^{2}$ Department of Internal Medicine, Datta Meghe Institute of Medical Sciences (Deemed to be University), J. N. Medical College, Wardha, Maharashtra, India. ${ }^{3}$ Department of Internal Medicine, Datta Meghe Institute of Medical Sciences (Deemed to be University), J. N. Medical College, Wardha, Maharashtra, India. ${ }^{4}$ Department of Pathology, Datta Meghe Institute of Medical Sciences (Deemed to be University), J. N. Medical College, Wardha, Maharashtra, India. ${ }^{5}$ Department of Internal Medicine, Datta Meghe Institute of Medical Sciences (Deemed to be University), J. N. Medical College, Wardha, Maharashtra, India.
\end{abstract}

\section{INTRODUCTION}

The incidence of musculoskeletal tuberculosis accounts for about one-third of all cases of tuberculosis occurring in extra pulmonary sites. The involvement of sacroiliac joint is rare and is commonly seen in immunocompromised young adults. Here we report the case of a 22-year-old immunocompetent female who presented to us with breathlessness, cough, lower back pain on right side and high-grade fever of 15 days duration. HRCT showed miliary mottling of both the lungs. MRI hip with sacroiliac joints revealed sacroiliitis. A Mantoux test was positive with $22 \mathrm{~mm}$ induration after 48 hours. Sputum AFB was positive for Mycobacterium tuberculosis. Sputum CB-NAAT test was positive. Sacroiliac joint aspiration sample was positive for CB-NAAT. The patient was administered with antituberculous drugs after which her symptoms began to subside and CXR was found to be normal on subsequent follow ups.

Tuberculosis (TB) is one of the world's most devastating infectious diseases caused by Mycobacterium tuberculosis, affecting nearly one-third of the world's population.(1) India accounts for about $27 \%$ of total Global TB burden.(2) Tuberculosis of the musculoskeletal system, though accounts for only 1-3\% of total TB cases, (3) of which approximately $10 \%$ occurs at the sacroiliac joint. [4-7]

The majority of cases of hip TB presents as painful, restricted movements of the hip and there comes, the dilemma of accurate diagnosis as several pathologies may mimic this presentation.

Sacroiliac joint tuberculosis is frequently missed because of the cryptic symptoms.[8,9] Therefore, its unusual existence causes it to be easily missed and diverts attention toward other similar, common diseases.

Perthes disease, juvenile rheumatoid arthritis, transient synovitis, bleeding disorders, pyogenic arthritis etc., has to be differentiated. Similarly, in adult's avascular necrosis (AVN), degenerative and inflammatory conditions may pose a problem in the diagnosis. Delayed and ineffective procedures often occur and cause significant pain, severe damage and dysfunction of the sacroiliac joint. Surgery is necessary by then.[10] Early detection and treatment is therefore very important and hence Sacroiliac joint infection must be included in the differential diagnosis of lower back pain and meticulous history and clinical evaluation of the joint are essential.
Corresponding Author: Dr. Sourya Acharya,

Professor,

Department of Medicine,

Datta Meghe Institute of Medical Sciences, Deemed to be University,

Jawaharlal Nehru Medical College,

Sawangi, Meghe, Wardha-442001,

Maharashtra, India.

E-mail: souryaacharya74@gmail.com

DOI: $10.14260 / \mathrm{jemds} / 2020 / 400$

Financial or Other Competing Interests: None.

How to Cite This Article:

Sahu G, Verma R, Acharya $S$, et al. Coexistence of miliary tuberculosis with tubercular sacroiliitis in a young immunocompetent female. J. Evolution Med. Dent. Sci. 2020;9(24):1834-1837, DOI: $10.14260 / \mathrm{jemds} / 2020 / 400$

Submission 18-03-2020,

Peer Review 19-05-2020,

Acceptance 26-05-2020,

Published 15-06-2020.

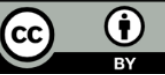




\section{PRESENTATION OF CASE}

A 22-year-old female presented to us with chief complains of fever and lower back since 15 days predominantly on the right side and gradual progressive dyspnoea since 7 days associated with expectoration, abdominal pain, chest pain, weight loss and loss of appetite. She had no known comorbidities and an unremarkable family and personal history.

On examination the patient was febrile with pulse 110 beats/min, Blood Pressure-110/70 and Respiratory rate was $32 /$ min with visible use of accessory muscle. Sp02 was $90 \%$. On systemic examination there was tachycardia and bilateral diffuse crackles were heard in both lung fields. CVS examination was normal.

On musculoskeletal examination: Right-sided gluteal and sacroiliac tenderness was elicited on deep palpation. Lateral pelvic compression, Patrick and Gaenslen's tests yielded positive findings on the affected side indicating musculoskeletal abnormality.

Investigations: $\mathrm{CBC}$ normal, Erythrocyte Sedimentation Rate (ESR) -140 mm in $1^{\text {st }}$ hour. Blood picture revealed a mild hypochromic and microcytic anaemia and haematocrit be $39.5 \%$. Liver function tests and Kidney function tests were normal. Slide agglutination tests with Dengue, leptospira, scrub typhus and Brucella antiserum were negative. Tuberculin skin test was positive $(22 \mathrm{~mm})$.

Chest X-ray (CXR) showed B/L Lung infiltrates (Figure-1) and high-resolution computed tomography (HRCT) lung showed miliary mottling of both lungs. Sputum AFB was positive for Mycobacterium TB. MRI hip with sacroiliac joints showed features of right sacroiliitis. (Figure-2)

Extensive debridement of the lesion was done along with an open biopsy over the right greater trochanter through a lateral approach. The gross specimen was soft, friable, whitishgrey, giving an impression of caseous cheese-like material. Direct smear microscopy revealed acid-fast bacilli and histopathological examination added evidence with a granulomatous infection. Polymerase Chain Reaction (PCR) has been used to amplify the genome of M. tuberculosis. Diagnosis of tuberculosis was ascertained by presence of $M$. tuberculosis in Lowenstein-Jensen culture medium

Two weeks after the administrations of AKT the fever decreased breathlessness improved. CXR was improved. Her hip pain improved significantly. ATT was continued and she was discharged and is awaiting follow up.

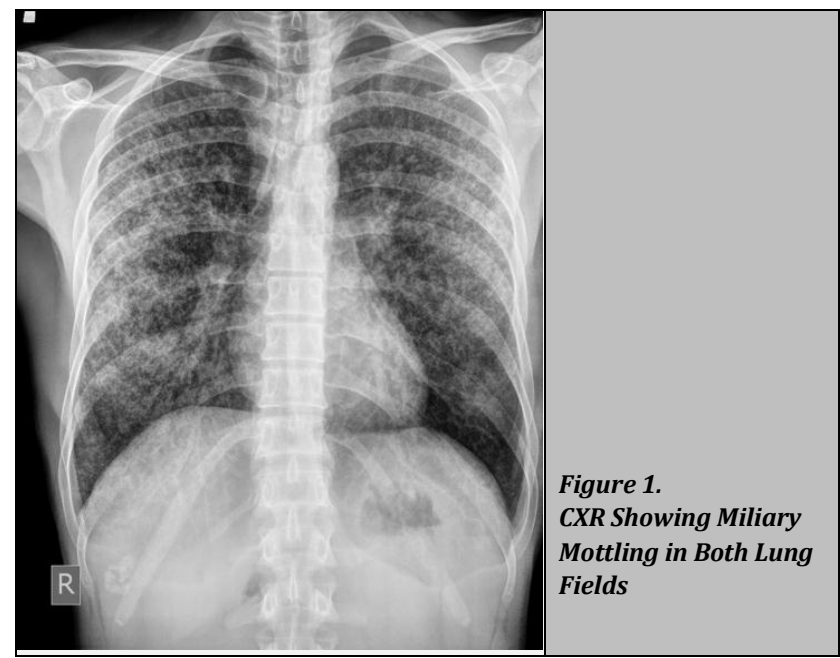

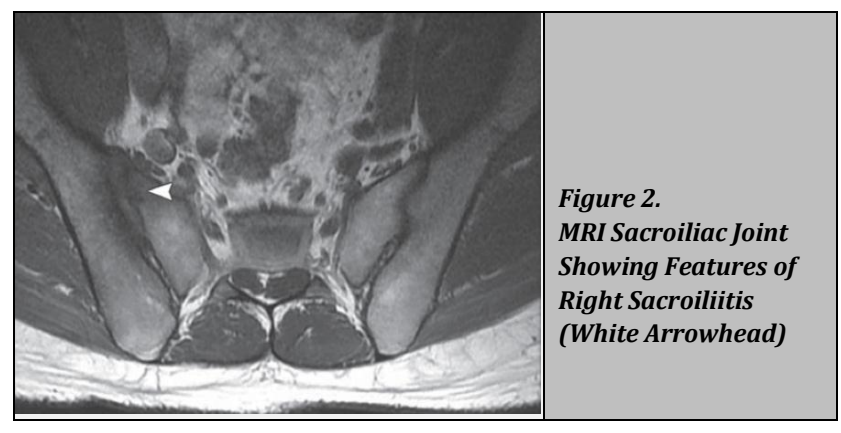

DISCUSSION

Clinical manifestations of miliary TB are most likely to be subacute or chronic; less commonly, acute presentations also occur. Patients with subacute or chronic disease may present with failure to thrive,[11] fever of unknown origin.[12,13] and/or dysfunction of one or more organ systems.[14] Night sweats are frequent; rigors are unusual.[15,16] Acute miliary TB may be fulminant, including multi organ system failure.[17] of all tuberculosis cases, spinal presentation of TB being a rare entity occurs due to spread of infection via hematogenous route either from a pulmonary or extra pulmonary site; Usually $50 \%$ of cases of spinal tuberculosis are associated with pulmonary infection. Sometimes one may even find such case in the absence of a pulmonary infection. ${ }^{[18]}$

Age of the patient is one of the important factors deciding the clinical presentation of sacral tuberculosis. Adults usually present with severe lower backache

Clinically evident radiculopathy and neurodeficit are usually less frequent because, the sacral nerve roots are protected by bone.[19,20] Due to this nonspecific symptomatology diagnosis is often delayed.[21]

Inaccessibility of the sacroiliac joint in supine position and physician's failure to perform the pain provocation manoeuvre on sacroiliac joint often leads to delayed diagnosis.[22]

Due to vague manifestations it is often difficult to diagnose tuberculous sacroiliitis accurately. Therefore, other causes of arthritis such as degenerative or post traumatic differentials should always be kept in mind. Other DDs like pyogenic infections of the joint; ankylosing spondylitis, Reiter, psoriatic arthritis and Bechet syndrome; Rheumatoid arthritis and SLE; metabolic syndrome like pseudogout and gout; tumour and tumour like conditions.[23,24,25,26,27]

Magnetic resonance imaging proves to be sensitive investigational tool, and a wide array of radiological spinal TB is well documented in the literature. MRI of the sacrum typically shows bone marrow oedema that is hypointense on T1- and hyper intense on T2-weighted images, ${ }^{[28,29]}$ indicating some underlying pathology. Tubercular lesions in MRI may be misinterpreted with other infectious or neoplastic diseases. This could be a cause of delays and errors in diagnosis.[29,30]

Histopathological study confirms the diagnosis of tuberculosis.[31] We confirmed the diagnosis of TB sacroiliitis by histopathologic examination.

Various chemotherapy methods have been proposed for the diagnosis of spinal tuberculosis. Management includes anti-tubercular drug regimen which comprises cumulation of four drugs: rifampicin, isoniazid, pyrazinamide and ethambutol for two months, accompanied by biotherapy.[32] 
Some evidence recommends chemotherapy for 6 months, while others recommend treatment with ATT for 9 to 12 months.[33] Response to medical management is usually adequate, and very few require surgical therapy. Antitubercular treatment and bed rest helped demonstrate a complete recovery in our patient.

Indications of surgery are; overwhelming signs of neurological compression due to extensive destruction of several vertebral bodies with a spinal deformity or to evacuate an abscess that is resistant to medical treatment. Prognosis of sacral TB is excellent if it is diagnosed early and therapy is initiated early in the course of the disease.[33]

In any phase of the pathologic lesion in sacrum or coccyx, particularly in areas where tuberculosis is prevalent, this pathology should always be apprehended in order to mitigate the morbidity of this potentially curable disease.

\section{CONCLUSIONS}

Clinical manifestations of infectious sacroiliitis usually lead to delayed diagnosis. Aetiology of sacroiliitis may vary from infectious causes to collagen vascular disorders especially spondylitis arthropathies.

Unilaterality usually favours infectious aetiology, while dealing with cases of unilateral sacroiliitis along with other suggestive features of infection, tuberculosis should be entertained as a possibility. As conclusive evidence of the study, in any clinical settings marked by lumbogluteal pain and signs of an infectious condition, such as fever, we recommend conducting an MRI of the spine and sacroiliac joint based on the findings. Tuberculosis still remains an important differential. ATT results in prompt recovery.

\section{REFERENCES}

[1] Babhulkar SS. Clinical comment. Clin Orthop 2002;398:23.

[2] Global Tuberculosis Report 2019. http://www.who.int/tb/publications/global_report/en/

[3] Tuli SM. tuberculosis of the skeletal system (Bones, Joints, Spine and Bursal sheaths). $4^{\text {th }}$ edn. New Delhi: Jaypee Brothers Medical Publishers Pvt Ltd 2010:69-110.

[4] Davies PD, Humphries MJ, Byfield SP, et al. Bone and joint tuberculosis. A survey of notifications in England and Wales. J Bone Joint Surg Br 1984;66(3):326-30.

[5] Goldberg J, Kovarsky J. Tuberculous sacroiliitis. South Med J 1983;76(9):1175-6.

[6] Martini M, Ouahes M. Bone and joint tuberculosis: a review of 652 cases. Orthopedics 1988;11(6):861-6.

[7] Nicholson RA. Twenty years of bone and joint tuberculosis in Bradford. A comparison of the disease in the indigenous and Asian populations. J Bone Joint Surg Br 1974;56-B(4):760-5.

[8] Gordon G, Kabins SA. Pyogenic sacroiliitis. Am J Med 1980;69(1):50-6.

[9] Pouchot J, Vinceneux P, Barge J, et al. Tuberculosis of the sacroiliac joint: clinical features, outcome, and evaluation of closed needle biopsy in 11 consecutive cases. Am J Med 1988;84(3 Pt 2):622-8.
[10] Papadopoulos EC, Papagelopoulos PJ, Savvidou OD, et al. Tuberculous sacroiliitis. Orthopedics 2003;26(6):653-7.

[11] Proudfoot AT, Akhtar AJ, Douglas AC, et al. Miliary tuberculosis in adults. Br Med J 1969;2(5652):273-6.

[12] Kim JH, Langston AA, Gallis HA. Miliary tuberculosis: epidemiology, clinical manifestations, diagnosis, and outcome. Rev Infect Dis 1990;12(4):583-90.

[13] Ansari NA, Kombe AH, Kenyon TA, et al. Pathology and causes of death in a group of 128 predominantly HIVpositive patients in Botswana, 1997-1998. Int J Tuberc Lung Dis 2002;6(1):55-63.

[14] Asada Y, Hayashi T, Sumiyoshi A, et al. Miliary tuberculosis presenting as fever and jaundice with hepatic failure. Hum Pathol 1991;22(1):92-4.

[15] Harvey C, Eykyn S, Davidson C. Rigors in tuberculosis. Postgrad Med J 1993;69(815):724-5.

[16] Lowry KJ, Stephan KT, Davis CE. Miliary tuberculosis presenting with rigors and developing unusual cutaneous manifestations. Cutis 1999;64(1):23-8.

[17] Sydow M, Schauer A, Crozier TA, et al. Multiple organ failure in generalized disseminated tuberculosis. Respir Med 1992;86(6):517-9.

[18] Kim DU, Kim SW, Ju CI. Isolated coccygeal tuberculosis. J Korean Neurosurg Soc 2012;52(5):495-7.

[19] Patankar T, Krishnan A, Patkar D, et al. Imaging in isolated sacral tuberculosis: a review of 15 cases. Skeletal Radiol 2000;29(7):392-6.

[20] Kumar A, Varshney MK, Trikha V. Unusual presentation of isolated sacral tuberculosis. Joint Bone Spine 2006;73(6):751-2.

[21] Gupta P, Prakash M, Sharma N, et al. Computed tomography detection of clinically unsuspected skeletal tuberculosis. Clin Imaging 2015;39(6):1056-60.

[22] Gordon G, Kabins SA. Pyogenic sacroiliitis. Am J Med 1980;69(1):50-6.

[23] Coy JT, Wolf CR, Brower TD, et al. Pyogenic arthritis of the sacro-iliac joint. Long-term follow-up. J Bone Joint Surg Am 1976;58(6):845-9.

[24] Bernard TN, Cassidy JD. The sacroiliac joint syndrome. Pathophysiology, diagnosis, and management. In: Frymoyer JW, ed. The adult spine: principles and practice. Philadelphia: Lippincott-Raven 1997:2343-66.

[25] Davidson PT, Horowitz I. Skeletal tuberculosis. A review with patient presentations and discussion. Am J Med 1970;48(1):77-84.

[26] Severe right hip pain in a 73-year-old woman. Am J Med 1986;81(1):117-24.

[27] Moujtahid M, Essadki B, Lamine A, et al. Tuberculous osteitis in limbs. Twenty five case-reports. Rev Rheum Engl Ed 1996;63(5):344-8.

[28] Resnick D, Niwayama G. Osteomyelitis, septic arthritis, and soft tissue infection: organisms. In: Resnick D, ed. Diagnosis of bone and joint disorders. Philadelphia: Saunders 1995:2461-85.

[29] Kim NH, Lee HM, Suh JS. Magnetic resonance imaging for the diagnosis of tuberculous spondylitis. Spine (Phila Pa 1976) 1994;19(21):2451-5.

[30] Wellons JC, Woods CW, Eastwood JD, et al. Sacral tuberculosis: a case report and review of the literature. Surg Neurol 2004;61(2):136-9. 
[31] Burrill J, Williams CJ, Bain G, et al. Tuberculosis: a radiologic review. Radiographics 2007;27(5):1255-73.

[32] Lazrak F, Abourazzak FE, Elouzzani FE, et al. A rare location of sacral tuberculosis: a report of three cases. Eur J Rheumatol 2014;1(2):78-80.

[33] Oniankitan O, Fianyo E, Kakpovi K, et al. Sacrum Pott's disease: a rare location of spine tuberculosis. The Egyptian Rheumatologist 2014;36(4):209-11.
[34] Lazrak F, Abourazzak FE, Elouzzani FE, et al. A rare location of sacral tuberculosis: a report of three cases. Eur J Rheumatol 2014;1(2):78-80.

[35] Punia VPS, Kumar S. Atypical manifestation of sacral tuberculosis as cauda-conus syndrome. JIACM 2008;9(1):57-60. 